\title{
Full Cost of Air Travel in the California Corridor
}

\author{
DAVID GILLEN AND DAVID LEVINSON
}

\begin{abstract}
The theoretical and empirical literature on the cost structure of the provision of air transportation is reviewed, and cost functions for air travel in the California corridor are specified and estimated. A full cost model is developed; it identifies and measures key cost components-fuser, carrier, infrastructure, time and congestion, noise, accident, and pollution costs. Applying the models to data for domestic air travel in the California corridor, the total long-run average cost is estimated to be 11 cents per passenger $\mathrm{km}$ traveled. The single largest cost category is owning and operating a plane. In general, because of large fixed-cost components, the average cost of infrastructure exceeds the marginal cost.
\end{abstract}

Sound investments in new transportation infrastructure depend on the full cost of providing and maintaining the transportation system today, including social, carrier, infrastructure, and user costs. Identifying what portion of total cost users currently pay, and what share others bear, allows us to avoid inefficient cross subsidies between modes, user groups, or regions. The development of cost models and estimates of the type presented in this research are essential to gauging the true costs of transportation.

This study develops and estimates long- and short-run average and marginal cost functions of air passenger transportation services and applies these models to estimate the full cost of domestic air travel in the California corridor. Social, or external, costs include noise, air pollution, safety or accident, and congestion costs. User costs comprise the cost of travel time, airfares, which are simply a transfer to airlines, and passenger taxes, which are, similarly, transfers to infrastructure operators. To avoid double counting, transfers are excluded. Airlines incur carrier costs of providing services by owning, operating, and maintaining fleets of aircraft. The costs of the airport and the air traffic control system are ascribed to infrastructure.

\section{LITERATURE REVIEW}

Many studies have been directed at determining the functional relationship between total per-unit operating costs and firm size in airlines (1-7). All studies have shown that economies to scale are roughly constant; thus, size does not generate lower per-unit costs. In particular, Gillen et al. $(6,7)$ found that the airline industry experienced economies of traffic density; that is, the unit cost would decrease for all carriers if they carried more traffic within their given network. The results also indicated that the unexploited economies of density are larger for low-density carriers. Caves et al. (3) include a network size variable in the cost function, along with output, to allow for the distinction between economies of scale and economies of density. McShan and Windle (5) extend the Caves et al. model and

D. Gillen, Institute of Transportation Studies, Room 109, McLaughlin Hall, University of California at Berkeley, CA 94720. D. Levinson, Department of Civil Engineering, University of Minnesota, 500 Pillsbury Drive SE, Minneapolis, MN 55455. explicitly account for the hub and spoke configuration that has developed in the United States since deregulation in 1978. They estimated a long-run cost function and found economies to density of about 1.35. The hubbing variable indicates that, all other things equal, a carrier with 1 percent more of its traffic handled at hub airports expects to enjoy a cost that is 0.11 percent lower than that of similar carriers.

On the airport infrastructure side, economists have typically assumed that capacity expansion is divisible. Morrison (8), in his analysis of optimal pricing and investment in airport runways, uses a sample of 22 busy U.S. airports to demonstrate that airport capacity construction is characterized by no economies of scale. In the literature, there is no empirical evidence on the cost characteristics of capacity construction of new small airports or capacity expansion of existing small airports. Gillen and Lall (9) show that the economies of scale for airports are negligible when movements are used as the measure of output but that they exhibit significant cost economies when the number of passengers is the unit of output. They note that the economies of density at airports therefore arise from the use of large aircraft.

\section{FULL-COST CALCULATION}

The full-cost calculation includes the infrastructure, carrier, user, and social costs. This paper represents each of those cost components in turn. The full cost (FC) of an air trip is the sum of the airport costs, including $(a)$ infrastructure construction cost (ICC) and operation and maintenance of terminals and airside facilities (IOC); (b) the cost of providing services by the air carrier or carrier costs (CC); (c) the costs of providing air traffic control (ATC) and air navigation costs (ANS) by the FAA; and (d) the social costs of air pollution (SPC), noise (SNC), congestion (SCC), accidents (SAC), and user time costs (UTC). This is represented in Equation 1:

$$
\begin{aligned}
\mathrm{FC}= & \alpha_{1}(\mathrm{ICC}+\mathrm{IOC})+\alpha_{2}(\mathrm{ATC}+\mathrm{ANS})+\alpha_{3}(\mathrm{CC})+\alpha_{4}(\mathrm{SPC}) \\
& +\alpha_{5}(\mathrm{SNC})+\alpha_{6}(\mathrm{SCC})+\alpha_{7}(\mathrm{SAC})+\alpha_{8}(\mathrm{UTC})
\end{aligned}
$$

In this full-cost measure, commercial passengers are responsible for only a portion of the costs of airport infrastructure, air traffic control and air navigation, and carrier operations. For example, airport infrastructure is used by cargo, general aviation, and military users, and the costs attributable to these users should not necessarily be allocated to commercial passengers. In the full-cost equation, we have indicated that the costs need to be weighted or apportioned among users. These weights are represented by the $\alpha_{i}$ 's, and the weights are not necessarily constant across cost components. From this stylized general relationship, we provide measures of the shortand long-run average and marginal costs of passenger trips by air. 
Other costs, such as landing fees and passenger facilities costs, that are added to passenger tickets are really transfers from one sector of the air economy to another. To avoid double counting, they are not included here.

\section{AIRWAY INFRASTRUCTURE AND OPERATING COSTS}

The FAA provides several user groups with essentially four services: air route traffic control centers, terminal radar control areas, air traffic control towers, and flight service stations. The unit costs of airway services were estimated and allocated to user groups in studies that were conducted for the FAA $(10,11)$. These differed from all previous approaches to cost measurement and allocation because cross-sectional statistical cost functions were used to estimate the cost of providing specific services to specific classes of people by facility type. The studies failed to include measures of capital costs; however, given the age of the airway system capital, it is not clear that our estimates will be significantly biased. The reasoning is that, with "vintage" capital, the capital-labor ratio will be lower than with newer capital. Thus, what we miss in capital cost will show up in operating costs. Ideally, however, we would like to have an economic measure of annual capital costs included in the cost function.

Golaszewski (10) provides a detailed description of the construction of the cost estimates for ATC services for four types of services/ facilities: air route traffic control centers (ARTCC), terminal radar control areas (TRACONS), air traffic control towers (ATCT), and flight service centers (FSS). These services are provided to different user groups or beneficiaries, and the groups contain subcategories based on differing criteria.

This study focuses primarily on the domestic air carrier user group. This, of course, means that the proportion of the costs that are "attributable" to this group must be determined. Table 1 gives the detailed cost allocation for domestic air carriers. Operating site costs include labor, maintenance, and leased communication at air traffic control facilities. Facilities and equipment costs consist of capital expenditures to replace or improve airport and airway facilities and equipment. Research and development (R\&D) includes FAA expenditures on R\&D programs to build and maintain a "safe, efficient airport and airway system." Airport grants comprise development funds given to sponsors of primary, commercial services and reliever and general aviation airports. Navaid Maintenance and Regulatory costs are those that the FAA incurs in providing and maintaining navigational equipment not located at operating sites and in regulating airmen, aircraft operations and manufacturing, and airports. Overhead includes costs for headquarters, regional administration, and procurement.

These cost categories formed the basis of the ATC cost functions. However, ATC equipment and maintenance costs, R\&D expenditures, and general overhead were not included in the variable cost estimates and were allocated across users on a Ramsey pricing basis. The Ramsey method employs the inverse of the elasticity of demand for facility use to allocate overheads to obtain economically efficient prices. As Golaszewski (10) reports, the major cost categories included were site labor costs, site maintenance costs, and site communications costs. He also reports that no capital costs were included because the FAA expenses the capital cost in the year of purchase.

The marginal cost estimates are developed by calibrating several linear cost functions for each of the four categories identified above.
TABLE 1 Cost Allocation to Domestic Air Carriers and Expense Category (10)

\begin{tabular}{|c|c|c|}
\hline Category & Total $(\$ M)$ & Air Carrier \\
\hline Domestic & & \\
\hline Direct Cost-Public Interest & 30 & 0 \\
\hline Navaid Maintenance & 467 & 166 \\
\hline Safety Regulation & 152 & 53 \\
\hline ARTCC & 680 & 276 \\
\hline ATCT & 136 & 10 \\
\hline TRACONS & 632 & 242 \\
\hline FSS & 288 & 13 \\
\hline Total Operating Site Costs & 2385 & 760 \\
\hline Facilities \& Equipment & 1632 & 807 \\
\hline $\mathrm{R} \& \mathrm{D}$ & 319 & 190 \\
\hline AIP Grants & 1111 & 574 \\
\hline Total Direct Costs & 5447 & 2331 \\
\hline Indirect Costs & 846 & 285 \\
\hline Total Costs & 6293 & 2615 \\
\hline
\end{tabular}

NOTE: Costs updated to $1994 \$ M . A I P=$ Airport Improvement Program

The empirical results are not reproduced here, but the tables that identify the marginal and unit cost measures are. It is these measures that are aggregated in the full-cost measure. These estimates are based on a series of calibrated multiple-output cost functions, but they fail to include input costs, a size measure to control for heteroscedasticity, or a measure of traffic density. The use of weighted least squares would be appropriate in the estimations, but it is not clear from the discussion whether anything beyond ordinary least squares was employed.

Table 2 (10) reports the final cost calculations for the air traffic control system. The dollar magnitudes were adjusted to 1994 dollars. In the first three columns of Table 2, the short-run marginal, joint, and long-run marginal costs are provided for domestic air carriers as estimated by Golaszewski (10). The difference between the short-and long-run marginal costs is that the long-run marginal costs allocate joint costs that are excluded from the short-run costs. Average costs (per air traffic control handle) are obtained by taking total costs and dividing by the number of aircraft departures.

\section{AIRPORT INFRASTRUCTURE AND OPERATING COSTS}

The costs of using airport resources can be divided into terminal costs and airside costs. The reason for dividing the two is that terminals are used by passengers, with the costs wholly attributable to commercial air services, whereas the airside resources are a function of aircraft movements. Aircraft movements include scheduled commercial, 
TABLE 2 Air Traffic Control: Marginal, Joint, and Unit Costs by Facility (10)

\begin{tabular}{lrrrr}
\hline Facility Type & $\begin{array}{c}\text { Short Run } \\
\text { Marginal } \\
\text { Costs }\end{array}$ & Joint Costs & $\begin{array}{c}\text { Long Run Marginal } \\
\text { Costs }\end{array}$ & Average Costs \\
\hline ARTCC (IFR Departure) & $\$ 297.64$ & $\$ 57.30$ & $\$ 354.94$ & $\$ 185.33$ \\
TRACON (per operation) & $\$ 206.32$ & $\$ 104.95$ & $\$ 311.28$ & $\$ 85.15$ \\
ATCT (per operation) & $\$ 2.89$ & $\$ 10.05$ & $\$ 12.95$ & $\$ 52.63$ \\
FSS: $\quad$ IFR Flight Plan & $\$ 13.64$ & $\$ 2.62$ & $\$ 16.25$ & $\$ 45.63$ \\
& & & & $\$ 25.74$ \\
\hline
\end{tabular}

NoTE: Costs updated to $1994 \$ M$. IFR = Instrument Flight Ruler

commuter, general aviation, and military. Furthermore, the majority of aircraft also carry freight (cargo and mail) in their belly. Therefore, there is joint production, and some portion of airside costs may be attributable to nonpassenger outputs. As in the case of airway cost calculations, all of the airside costs cannot be allocated to scheduled commercial (passenger) air services. To determine the appropriate allocation, economic cost functions in which the airside costs are regressed on each type of movement are estimated. The second distinction that is made, as elsewhere, is short- versus long-run costs. In the former, existing infrastructure is treated as noncongested, and an estimate is made of the cost of servicing an additional passenger or additional movement. The long-run estimates include a measure of the capital costs; thus, the marginal and average cost figures are those associated with expansion of the airside (or terminal) system when additions to capacity must take place.

\section{Terminal Costs}

Estimates of terminal costs were developed from data for 22 large airports, with each airport having data for a 5-year period (110 observations). In addition, a panel was used, which reduced the problems associated with either exclusive time series or cross-sectional data.

Table 3 presents the final estimates for both long- and short-run terminal costs. Alternative functional forms, as well as dummy variables for some airports, were tested but were insignificant in the outcome. The simple arithmetic relationship had the best statistical fit.
The long-run cost relationship is illustrated in Table 3. Total costs - capital plus operating costs - were regressed on values for passengers. The researchers were not able to distinguish between domestic and international passengers. It would be expected that airports with greater proportions of international passengers would have higher costs. The model that had the best statistical fit was the simple linear model. In these estimates, neither the second-order term nor the constant term was statistically significant. The estimates of the long-run marginal cost are $\$ 5.72$ per passenger. The simple average taken from the sample, total costs divided by the number of passengers, was $\$ 7.45$ per passenger.

For the short-run costs in Table 3, the constant term is significant, indicating the presence of fixed costs and indicating that the parameter estimates on the linear and second-order term are both statistically significant at the 10 percent level. The results indicate that short-run marginal costs are rising at a relatively constant rate; the second-order coefficient is not significant. The marginal cost per passenger is $\$ 1.62$, while the average cost per passenger would be (\$924358/\# passengers) + \$1.62. \$924358 is a constant term representing the allocation of the fixed costs. Because the marginal is less than the average cost, there are some cost economies with increasing passengers. Interestingly, the calculated average variable cost per passenger was $\$ 4.25$.

How do these numbers compare with previous estimates? There are relatively few investigations against which to compare this work. A Canadian study used an engineering approach to develop a measure of $\$ 10.24$ per passenger for terminal services in the period 1990

TABLE 3 Long- and Short-Run Terminal Costs

\begin{tabular}{lrr}
\hline $\begin{array}{c}\text { Dependent Variable } \\
\text { Independent Variable: }\end{array}$ & Long Run Total Cost & Short Run Terminal O\&M Costs \\
\hline $\mathrm{C}$ & 118849. & 924358. \\
& $(.589)$ & $(3.14)$ \\
Passengers & 5.72 & 1.64 \\
& $(4.72)$ & $(3.07)$ \\
Passengers squared & $-.139 \mathrm{E}-06$ & $.366 \mathrm{E}-06$ \\
& $(-1.55)$ & $(1.79)$ \\
Adjusted R-squared & .820163 & .934831 \\
F-statistic (zero slopes) & 55.7271 & 173.137 \\
Log of likelihood function & -366.985 & -376.417 \\
\hline
\end{tabular}

NOTE: Numbers in parentheses () indicate t-statistic 
to 1993 , when converted to 1994 U.S. dollars (12). This compares to the measure in this study of $\$ 5.72$ per passenger.

\section{Airside Costs}

The researchers undertook a similar analysis for estimates of airside costs. In this case, it was important to be able to both establish a measure of the appropriate short-and long-run costs and allocate costs across the different user groups. The estimates were developed from the sample of 22 airports. As before, parameters were estimated on the basis of a "variable" cost model in which capital (capacity) is considered a quasi-fixed factor of production, and the adjustments to output are made using the variable factors; hence, variable costs. In a subsequent model, measures of total cost (capital plus operating) were used, and the long-run cost relationships were estimated.

Table 4 reports estimates for the long- and short-run models. For the long run, the estimates used the sum of capital and operating costs. The long-run marginal cost is $\$ 117.10$ for air carriers, $\$ 22.43$ for commuters, and $\$ 17.08$ for general aviation. For the second and third user groups, there is a relatively small increase in the marginal cost from the short-run estimates. It is also evident from the estimates that, like Morrison, there is evidence of approximately constant returns to scale. This means that size confers neither an advantage nor a disadvantage on the costs of airside facilities. However, this is not true in the case of terminals, where some evidence is found of falling costs with capacity utilization. Calculating the simple average total cost, a figure of $\$ 93.84$ is obtained.

For the short-run model, the total operating and maintenance cost was regressed on numbers of movements for scheduled air carrier, commuter, and general aviation, as well as airport-specific dummy variables. Second-order terms were also investigated, but they were not statistically significant. The simple linear model seemed to perform as well as others. The short-run marginal cost of a scheduled air carrier movement is $\$ 81.87$, for a commuter carrier it is $\$ 17.87$, and for general aviation it is $\$ 12.57$. Using the data from the U.S. airports, the measured simple average variable cost is $\$ 43.66$ per movement (not distinguishing between general aviation, commuter, and air carriers). Morrison (8) estimated the short-run marginal cost of an air carrier operation as $\$ 25.34$ when expressed in 1994 dollars. This figure would be compared against this study's short-run marginal cost per movement of $\$ 81.87$.

The researchers also undertook a simple examination of the composite airport costs, airside plus terminal. The simple averages were $\$ 5.99$ average variable cost per passenger and \$201.99 per movement. These numbers are used frequently when illustrating differences between air and other modal costs. However, these numbers are biased in that they reflect composite outputs and have not taken into consideration the full-cost responsibility across outputs for terminals and airside facilities.

\section{CARRIER COSTS}

Two approaches can be taken in constructing the carrier cost function. One is to estimate an econometric cost function in which outputs, input prices, and levels of technology are contained in the cost function derived from some underlying production function and the optimizing behavior of firms (6). This aggregate approach is useful for understanding the characteristics of the underlying production structure, input substitution, scale and scope economies, and cost efficiency. These measures are important in long-term decision making regarding mergers, network structure and size, and input substitution, but they are too aggregate for the purposes of this study. Determining what the cost would be to add another passenger or flight to the segment in an existing network can be directly related to pricing decisions. The researchers proceed to estimate a statistical cost function in which the additional costs of carrying another passenger is determined in cases with and without capacity expansion.

\section{Measurement of Segment Cost}

In describing a carrier's costs, costs that vary by segment and those that vary by route are distinguished. It is also necessary to be able to calculate unit cost per passenger for the short and long run. In this way

TABLE 4 Long- and Short-Run Airside Costs

\begin{tabular}{lll}
\hline $\begin{array}{c}\text { Dependent Variable: } \\
\text { Independent Variable: }\end{array}$ & Long Run Total Costs & Short Run O \& M Costs \\
\hline C & -271559. & -297116. \\
& $(-0.47)$ & $(-1.02)$ \\
Scheduled Carriers & 117.10 & 81.87 \\
& $(2.96)$ & $(4.13)$ \\
Commuter Aircraft & 22.43 & 17.57 \\
& $(2.66)$ & $(4.16)$ \\
Total General Aviation & 17.08 & 12.49 \\
& $(1.68)$ & $(2.45)$ \\
Adjusted R-squared & .842 & .855 \\
F-statistic (zero slopes) & 27.66 & 30.62 \\
Log of likelihood function & -311.927 & -297.413 \\
\hline
\end{tabular}

NOTE: Numbers in parentheses () indicate -statistic 
it is possible to examine the cost differences for adding a passenger, a flight, and a route segment. For route segments, the source of cost differences will be in the airline system or station costs. For example, if carrier $i$ were to extend its operation from Point $\mathrm{B}$ to Point $\mathrm{C}$, when it was already in market between points $\mathrm{A}$ and $\mathrm{B}$, the additional costs would include the increase in flight operating costs and passenger costs. However, since it is already serving Airport B, the cost of adding an operation will be quite low. This is quite different from a circumstance of entering an entirely new market. Clearly, both the volume of passengers and the flight frequency are important for all measures of cost. Total cost for a flight segment $C^{T}$ can be written as

$$
C^{T}=C^{q}(q)+C^{f}(f)
$$

where $q$ is the total number of passengers on a segment, and $f$ is the flight frequency on that segment.

The first term of Equation 2 is related to passengers, and the second term is associated with flight frequency.

\section{Passenger and Flight-Related Costs on a Segment}

Indirect (or passenger) costs on a segment were obtained from Form 41 data by subtracting flight-related costs from total costs (corrected to properly account for capital costs). These calculated total indirect costs were allocated to each segment by multiplying systemwide total indirect costs by the ratio of segment revenue to systemwide total revenue. The total indirect cost for a flight segment, which would involve the California market, was estimated by allocating the carrier's total indirect costs in proportion to the revenue generated from the particular route segment. Then the proportion of the airlines' systemwide indirect costs attributable to the California market were allocated. Typically, indirect costs will be anywhere from 45 to 60 percent of total costs, so the estimate of $\$ 0.04 /$ passenger $\mathrm{km}$ traveled derived here is not an unreasonable figure.

The flight-related costs can be measured by adding the cost per block-hour multiplied by the number of block-hours required for the flight segment and a measure of the opportunity costs of flight capital. The Form 41 data do not provide an accurate measure of the economic costs of capital invested in aircraft. Therefore, the block-hour costs need to be adjusted upward by the amount of interest cost on the capital tied up in the aircraft (the opportunity cost of flight capital).

The treatment of these two costs as constant unit costs to the airline is analogous to the concept of constant marginal cost in the usual competitive model. These are unit flight costs and unit passenger costs, $w$ and $v$, respectively. Unit costs will change as the volume of passengers, flight frequency, and load factors change.

Total segment costs are then defined as

$$
C^{T}=C^{q}(q)+C^{f}(f)=v q+w f
$$

where $w$ is the unit flight cost, and $v$ is the unit passenger cost. Carrier load factors are calculated as follows:

$$
z=(q / f) / G
$$

where $z$ is the carrier load factor and $G$ is gauge (available seats or plane capacity).

Average per-passenger segment cost, $u$, can be computed by dividing the total segment cost by the number of passengers. The approximate average cost per passenger is obtained by dividing the total block-hour costs (flight costs) for the segment plus the total passenger costs by the number of segment passengers. Unit costs on a per-passenger basis are expressed as follows:

$u=C^{T} / q=(w f / q)+v=(w / G z)+v$

Table 5 (13-15) reports the block-hour costs for each of four representative types of aircraft that most likely would be used on domestic (California) routes. To this figure an amount needs to be added that reflects the opportunity cost of the flight capital. The difference between these two figures is the difference between short- and long-run costs. The calculations use an assumed load factor of 68 percent $(13,14)$, a stage length for the California corridor of $625 \mathrm{~km}$, and a speed of $877 \mathrm{~km} / \mathrm{h}$. Final calculations are based on the B737-300 series aircraft because it is the most popular on shorter-haul domestic routes in California. The short-run average and marginal (operating) cost is equal to the block-hour cost divided by seats, average load factor, and speed. The long-run average and marginal cost adds the opportunity cost of aircraft capital to the short-run operating costs.

\section{NOISE COSTS}

Noise due to aircraft is traditionally associated with airports and with aircraft flying overhead that are not in the process of takeoff or landing. Although the aircraft obviously generates the noise, the airport - the most convenient point of complaint - is typically held responsible. The annoyance caused by noise is due to a number of unique factors, including individual preferences, socioeconomics, environmental conditions, local topography, and number of flights. If noise annoyance is capitalized in land prices, we need only determine the noise coming from aircraft. Aircraft noise production is tied to its level of technology, or stage, which is related to its age and size. The technology determines total engine thrust needed and is thus an influence in noise production. Levesque (16), for instance, employs a Noise Exposure Forecast (NEF) to estimate the equivalent amount of noise produced by aircraft at an airport. Gillen (17) reports the number of impacted homes around airports. Levinson et al. (18) summarizes the depreciation in home value as a function of noise. Quinet (19) and the IBI Group (20) estimate the noise costs per passenger $\mathrm{km}$ traveled that are generated by air travel in eight countries. The average value for these results $-\$ 0.0043 /$ passenger $\mathrm{km}$ traveled-is used here.

\section{TRAVEL TIME AND DELAY COSTS}

Although others have estimated congestion models for airports, perhaps the most widely used approach is that of the FAA (21-23). Each airport has a rated capacity [annual service volume $\left(Q_{0}\right)$ ] based on runway designs and other physical factors. Delay per aircraft depends on the usage [in operations $(Q)$ ] of the airport relative to its capacity. The following average delay per aircraft $\left(D_{A}\right)$ (in minutes) was estimated using the FAA graphs:

$$
\begin{aligned}
& D_{A}=0.19+2.33\left(Q / Q_{0}\right)^{6} \\
& D_{T}=D_{A} * Q=0.19 Q+2.33\left(Q / Q_{0}\right)^{7} \\
& D_{M}=\partial D_{T} / \partial Q=0.19+16.31\left(Q / Q_{0}\right)^{6}
\end{aligned}
$$


TABLE 5 Carrier Costs per Block-Hour and Seat-Kilometer (13-15)

\begin{tabular}{|c|c|c|c|c|}
\hline Cost Category & $\mathrm{B} 737-300$ & $\mathrm{~B} 737-400$ & $\mathrm{~B} 737-500$ & MD-80 \\
\hline Crew Cost $(\$ / h)$ & 456 & 554 & 267 & 506 \\
\hline Fuel \& Oil & 425 & 428 & 403 & 484 \\
\hline Rentals & 423 & 585 & 319 & 310 \\
\hline Insurance & 11 & 19 & 12 & 11 \\
\hline Taxes & 17 & 20 & 23 & 22 \\
\hline Total Flying Operations & 1332 & 1608 & 1024 & 1333 \\
\hline Airframe Maintenance & 157 & 126 & 114 & 136 \\
\hline Engine Maintenance & 116 & 54 & 60 & 74 \\
\hline Maintenance Burden & 153 & 135 & 162 & 119 \\
\hline Total Maintenance & 426 & 315 & 336 & 329 \\
\hline Depreciation & 92 & 84 & 118 & 130 \\
\hline Other & 22 & 10 & 34 & 34 \\
\hline Total Block Hour Cost $(\$ / \mathrm{h})$ & 1872 & 2018 & 1512 & 1826 \\
\hline Avg. Seats per Flight & 131 & 144 & 112 & 139 \\
\hline Operating cost per seat $\mathrm{km}(\$)$ & 0.024 & 0.023 & 0.023 & 0.022 \\
\hline Price of Aircraft $(\$ M)$ & 27.9 & 31.6 & 26,8 & 27.5 \\
\hline $\begin{array}{l}\text { Annual Opportunity Cost of Capital at } 7.5 \text { percent } \\
(\$ \mathrm{M})\end{array}$ & 2.093 & 2.370 & 2.010 & 2.062 \\
\hline Total Block Hours & 3759.5 & 3759.5 & 3759.5 & 3759.5 \\
\hline Opportunity Cost per Block Hour $(\$ / \mathrm{h})$ & 556.59 & 630.40 & 534.65 & 548.61 \\
\hline Opportunity Cost per Seat km (\$) & 0.0071 & 0.0073 & 0.0080 & 0.0066 \\
\hline Long Run Cost per Seat km (\$) & 0.031 & 0.030 & 0.031 & 0.029 \\
\hline
\end{tabular}

NOTE: Assumes speed of $877 \mathrm{~km} / \mathrm{hr}$. load factor of $68 \%$

The total delay $\left(D_{T}\right)$ is simply the average delay multiplied by the number of aircraft $(Q)$. The marginal delay $\left(D_{M}\right)$ is the derivative of the total cost with respect to output $Q$.

The annual service volume is calculated from an FAA model that takes into consideration the airport's aircraft mix index, runway layout, percentage of time that runways are used in a specific operating condition (e.g., northeast parallels in Instrument Flight Rules weather), hourly runway capacity under that condition, and historic monthly traffic records. These are shown in Table 6 for California data. A question naturally arises as to the validity of a capacity model that has some airports regularly operating at levels substantially above their theoretical limit. Instead of trying to defend the accuracy of the modeled capacities, the researchers believe that the resulting annual service volumes can be used to index airports by taking into account their differing physical, climatological, and operating conditions.

To operationalize this measure, information was used from the series of airports that were included in the estimation of the airport costs. Each airport has an annual service volume figure, which was averaged. The average delay per flight is approximately $6.5 \mathrm{~min}$; with a $\$ 10 / \mathrm{h}$ value of time, this figure is $\$ 1.08 /$ passenger $(\$ 0.0017 /$ passenger $\mathrm{km}$ traveled). The marginal congestion costs, which in- clude those imposed on others, is $44.36 \mathrm{~min}$, or $\$ 7.39 /$ passenger ( $\$ 0.012 /$ passenger $\mathrm{km}$ traveled). The cost of user time is simply the travel time multiplied by the value of time, which was estimated at $\$ 0.0114 /$ passenger $\mathrm{km}$ traveled. The value of time is probably not linear; one person saving $60 \mathrm{~min}$ may be more valuable than 60 individuals each saving $1 \mathrm{~min}$. However, to analyze systemwide travel times, small delays need to be added together and may collectively approach larger time units for which monetization is a reasonable approach.

\section{ACCIDENT COSTS}

Aviation accident statistics are collected by the National Transportation Safety Board for the following, in descending order of safety: large airlines, commuter airlines, air-taxis, and general aviation. Because commercial air accidents are rare and vary a great deal in magnitude, accident rates are not stable on a yearly basis. A multiyear average of U.S. statistics gives a fatal accident rate of 0.00048 per million aircraft $\mathrm{km}$.

The human cost per accident can be approximated by the average fatality rate per fatal crash (13 fatalities per fatal crash) multiplied 
TABLE 6 Major Airports in California, Utilization, Capacity, Delay (18)

\begin{tabular}{|c|c|c|c|c|c|}
\hline ID & Airport Name & $\begin{array}{r}\text { Enplanements } \\
(000) 1991 \\
\end{array}$ & $\begin{array}{l}\text { Operations } \\
(000) 1991 \\
\end{array}$ & $\begin{array}{r}\text { Capacity }\left(Q_{0}\right) \\
(000) 1991 \\
\end{array}$ & $\begin{array}{r}\text { Average Delay } \\
\text { (min) }\end{array}$ \\
\hline LAX & Los Angeles & 22520 & 661 & 675 & 2.24 \\
\hline SFO & San Francisco & 15187 & 435 & 393 & 4.47 \\
\hline SAN & $\begin{array}{l}\text { San Diego/ } \\
\text { Lindbergh Field }\end{array}$ & 5617 & 260 & 225 & 5.73 \\
\hline SJC & San Jose & 3443 & 337 & 385 & 1.23 \\
\hline OAK & $\begin{array}{l}\text { Metropolitan } \\
\text { Oakland }\end{array}$ & 3013 & 414 & 625 & 0.39 \\
\hline ONT & Ontario & 2873 & 156 & 355 & 0.21 \\
\hline SNA & $\begin{array}{l}\text { John Wayne/ } \\
\text { Orange County }\end{array}$ & 2636 & 55.1 & 355 & 0.19 \\
\hline $\mathrm{SMF}$ & $\begin{array}{l}\text { Sacramento } \\
\text { Metropolitan }\end{array}$ & 2176 & 152 & 370 & 0.20 \\
\hline BUR & $\begin{array}{l}\text { Burbank/ Glendale/ } \\
\text { Pasadena }\end{array}$ & 1843 & 229 & 230 & 2.46 \\
\hline
\end{tabular}

NOTE: Enplanements is the number of people boarding; operations is the number of planes; capacity is capacity in number of planes; and average delay ( $\mathrm{min})$ is in minutes.

by the value of life $(\$ 2,700,000)$, or $\$ 35,100,000$, not including injuries and property damage. The cost per passenger is simply the fatal accident rate multiplied by the cost per accident divided by the number of passengers per flight (89). This results in a cost of $\$ 0.0001893 /$ passenger $\mathrm{km}$ traveled. Taking more conservative values of life and including nonlife costs (injury and medical, accident cleanup, etc.), and assuming a higher number of fatalities, the estimate could quadruple. This range is consistent with international estimates $(20,24)$.

\section{POLLUTION COSTS}

The pollution costs for air travel are hard to estimate because emissions are not localized. Combining the total emissions with an estimate of passenger kilometers traveled by jets in the United States produces an estimate of pollution per unit output, shown in Table 7 (25, Figure $3-1$, p. 50;26). The quantity of pollutants must be combined with damage per unit of pollutant. In the California corridor, a large share of the air trip is over urbanized areas (as are all emissions associated with takeoff and landing).

TABLE 7 Air Pollution Costs of Air Travel

\begin{tabular}{lrrr}
\hline Pollutant & $\begin{array}{r}\text { Emissions } \\
\mathrm{gm} / \mathrm{pkt}\end{array}$ & $\begin{array}{r}\text { Health Damage } \\
\$ / \mathrm{kg}\end{array}$ & $\begin{array}{r}\text { Costs } \\
\$ / \mathbf{k m}\end{array}$ \\
\hdashline $\mathrm{HC}_{\mathrm{N}}$ & 0.09 & $\$ 1.33$ & $\$ 0.00012$ \\
$\mathrm{CO}$ & 0.28 & $\$ 0.0063$ & $\$ 0.0000018$ \\
$\mathrm{NOx}$ & 0.13 & $\$ 1.33$ & $\$ 0.00017$ \\
Carbon & 100 & $\$ 0.0058$ & $\$ 0.00058$ \\
\hline TOTAL & & & $\$ 0.00087$ \\
\hline
\end{tabular}

Source: Emissions: Authors' Estimates, (25,26); Damage Costs: see (18) for details.
Consequently, damage estimates that were computed from auto travel in Los Angeles were applied, and a \$2.7 million value of life was assumed, consistent with the accident data above. The cost of air pollution caused by air travel (the health damages from particulates, sulfur oxides, hydrocarbons, carbon monoxide, and nitrogen oxides, plus the greenhouse damages due to carbon) is $\$ 0.00089 /$ passenger $\mathrm{km}$ traveled.

\section{SUMMARY AND CONCLUSIONS}

Table 8 summarizes the short- and long-run marginal and average costs by category in terms of cost per passenger km traveled. The difference between marginal and average cost is exceeded by the difference between the short and long run. Although this analysis was conducted for the California corridor, other stage length and aircraft types can be used with the methodology and data described in this paper to attain results for other corridors. The full cost of air travel per passenger $\mathrm{km}$ for the California corridor is $\$ 69$ for the trip from San Francisco to Los Angeles, which is in line with the current $\$ 59$ fare in the corridor. Because the cost estimates include social costs and user time costs, they are expected to be higher than the fares, which reflect only the cost to carriers, including the fleet and air system charges.

Because this research analyzed the full cost of air travel in California by examining each cost component, it enables a fair comparison between modes to ascertain which is most cost-effective for a given market. By comparing the costs of air transportation with those of high-speed rail (27), it was determined that the long-run average cost of air travel ( $\$ 0.11 /$ passenger $\mathrm{km}$ traveled) is significantly lower than a proposed high-speed rail line ( $\$ 0.24 /$ passenger $\mathrm{km}$ traveled) in the California corridor. This suggests that any excess social costs associated with air travel are more than compensated by its faster speed and lower capital costs. Although airports may need to be expanded, an entire rail corridor does not need to be constructed from scratch through mountain passes at great expense. Airports 
TABLE 8 Summary Costs of Air Travel in the California Corridor (\$/Passenger Kilometers Traveled [pkt])

\begin{tabular}{|c|c|c|c|c|}
\hline Cost Category & $\begin{array}{l}\text { Short Run } \\
\text { Marginal Cost }\end{array}$ & $\begin{array}{l}\text { Short Run } \\
\text { Average Cost }\end{array}$ & $\begin{array}{l}\text { Long Run } \\
\text { Marginal Cost }\end{array}$ & $\begin{array}{l}\text { Long Run } \\
\text { Average Cost }\end{array}$ \\
\hline \multicolumn{5}{|l|}{ Infrastructure: } \\
\hline \multicolumn{5}{|l|}{ Airways: } \\
\hline ARTCC & 0.0053 & 0.0034 & 0.0064 & 0.0034 \\
\hline TRACONS & 0.0037 & 0.0015 & 0.0056 & 0.0015 \\
\hline ATCT & 0.000052 & 0.0009 & 0.00023 & 0.0009 \\
\hline FSS & 0.000245 & 0.0008 & 0.00029 & 0.0008 \\
\hline \multicolumn{5}{|l|}{ Airport: } \\
\hline Terminal & 0.0026 & 0.0068 & 0.0092 & 0.012 \\
\hline Airside & 0.0015 & 0.00078 & 0.0021 & 0.0017 \\
\hline \multicolumn{5}{|l|}{ Carrier } \\
\hline Indirect Cost & 0 & 0.04 & 0 & 0.04 \\
\hline Capital Cost & 0 & 0 & 0.0071 & 0.0071 \\
\hline Operating Cost & 0.0240 & 0.0240 & 0.0240 & 0.0240 \\
\hline \multicolumn{5}{|l|}{ External } \\
\hline Accidents & 0.00019 & 0.00019 & 0.00019 & 0.00019 \\
\hline Congestion & 0.012 & 0.0017 & 0.012 & 0.0017 \\
\hline Noise & 0.0043 & 0.0043 & 0.0043 & 0.0043 \\
\hline Pollution & 0.00089 & 0.00089 & 0.00089 & 0.00089 \\
\hline \multicolumn{5}{|l|}{ User } \\
\hline Time & 0.0114 & 0.0114 & 0.0114 & 0.0114 \\
\hline Total Cost & 0.066177 & 0.09666 & 0.0837 & 0.10988 \\
\hline Trip Cost $(\$)$ & $\$ 41.36$ & $\$ 60.38$ & $\$ 52.31$ & $\$ 68.68$ \\
\hline
\end{tabular}

SOURCE: Authors' Calculations. NOTE: assumes $625 \mathrm{~km}$ trip, 131 seats per plane, load factor $=68 \%$

would exist whether or not they were serving the local travel in California; the additional marginal cost of serving in-state travel is relatively low. On the other hand, high-speed rail would not exist without the construction of this corridor; California is separated from other population centers by large distances not suited to train travel. More research is needed to increase both the accuracy and precision of each of these estimates, but this framework permits a straightforward calculation of the costs and clarifies where the major burden of costs fall. The amount of cross-subsidy then can be related to user charges.

\section{REFERENCES}

1. Douglas, G., and J. Miller. Economic Regulation of Domestic Air Transport: Theory and Policy. Brookings Institution, Washington, D.C., 1974.

2. Keeler, T. Airline Regulation and Market Performance. Bell Journal of Economics, Vol. 3, 1972, pp. 399-424.

3. Caves, D., L. Christensen, and M. Tretheway. Economies of Density Versus Economies of Scale: Why Trunk and Local Service Airline Costs Differ. Rand Journal of Economics, Vol. 15, No. 4, Winter 1984 pp. 471-489.

4. Caves, D., L. Christensen, M. Tretheway, and R. Windle. Network Effects and the Measurement of Returns to Scale and Density for U.S Railroads. In Analytical Studies in Transport Economics, Daughety (ed.), Cambridge University Press, Cambridge, England, 1985.
5. McShan, S., and R. Windle. The Implications of Hub-and-Spoke Routing for Airline Costs and Competitiveness. Logistics and Transportation Review, Vol. 35, No. 3, Sept. 1989, pp. 209-230.

6. Gillen, D., T. Oum, and M. Tretheway. Airline Cost and Performance: Implications for Public and Industry Policies. Centre for Transportation Studies, University of British Columbia, Vancouver, B.C., Canada, 1985.

7. Gillen, D., T. Oum, and M. Tretheway. Airline Cost Structure and Policy Implications: A Multi-Product Approach for Canadian Airlines. Journal of Transport Economics and Policy, Jan. 1990, pp. 9-33.

8. Morrison, S. Estimating the Long-Run Prices and Investment Levels for Airport Runways. Research in Transportation Economics, Vol. 1, 1983, pp. 103-131.

9. Gillen, D., and A. Lall. Economies of Scale for Airports. Working Paper. Wilfrid Laurier University, Waterloo, Ca., 1998.

10. Golaszewski, R. The Unit Costs of FAA Air Traffic Control Services. Journal of the Transportation Research Forum, Vol. 28, No. 1, 1987, pp. 13-20.

11. Taylor, D. Allocation and Recovery of Federal Airport and Airway Costs. FAA, U.S. Department of Transportation, 1992.

12. Directions. Royal Commission on National Passenger Transportation in Canada, Transport Canada, Ottawa, Ontario, 1994.

13. Costs: B 737-300 and MD-80. Aviation Daily. Aug. 12, 1995.

14. Costs: B 737-400 and B737-500. Aviation Daily. Aug. 14, 1995.

15. Bowman, L. Keep Up in Asia. Air Finance Journal. June 1994, pp. 32-36.

16. Levesque, T. Modeling the Effects of Airport Noise on Residential Housing Markets: A Case Study of Winnipeg International Airport. Journal of Transport Economics and Policy, Vol. 28, No. 2, 1994, pp. 199-210.

17. Gillen, D. The Management of Airport Noise. DWG Research Associates for Transport Development Centre, Transport Canada, Ottawa, Ontario, July 1990. 
18. Levinson, D., D. Gillen, and A. Kanafani. The Social Costs of Intercity Transportation: A Review and Comparison of Air and Highway. Transport Reviews, Vol. 18, No. 3, 1998, pp. 215-240.

19. Quinet, Emile. The Social Cost of Land Transport. OECD Environment Monograph No. 32, April 1990.

20. Full-Cost Transportation Pricing Study: Final Report to Transportation and Climate Change Collaborative. IBI Group, Boston, Mass., 1995.

21. Drake, J. Airline Network Efficiency: A Method of Analyzing Rationalized Networks with Applications to U.S. Examples. Purdue University Ph.D. Dissertation Series, Indianapolis, Ind., March 1978.

22. Kanafani, A., and A. Ghobrial. Airline Hubbing: Some Implications for Airport Economics. Transportation Research Report. Feb. 1985.

23. Airport Capacity and Delay. Report AC 150/5060-5, FAA, U.S. Department of Transportation, 1983.
24. Social Cost of Road Accidents in Australia. Economics Report 79, Australian Bureau of Transport and Communications, Australian Government Publishing Service, Canberra, 1992.

25. 1994 Annual Report. Bureau of Transportation Statistics, U.S. Department of Transportation, 1994.

26. Emissions of Greenhouse Gases in the United States 1987-1992. Energy Information Administration, Washington, D.C., Nov. 1994.

27. Levinson, D., J. Mathieu, D. Gillen, and A. Kanafani. The Full Cost of High-Speed Rail: An Engineering Approach. Annals of Regional Science, Vol. 31, No. 2, 1997, pp. 189-215.

Publication of this paper sponsored by Committee on Aviation Economics and Forecasting. 